\title{
Intellectual energy security monitoring of decentralized systems of electricity with renewable energy sources
}

\author{
Boris Lukutin ${ }^{1}$, Violetta Kiushkina ${ }^{2}$ \\ ${ }^{1}$ Tomsk National Research Polytechnic University School of Engineering Energy, Lenin str. 30, Tomsk, Russia \\ ${ }^{2}$ EA Technical Institute (branch) of the Northeast Federal University after M.K. Ammosova, Kravchenko str.16, Nerungri, Russia
}

\begin{abstract}
The article reveals an attempt to create an integrated information system for energy security monitoring, for instance in Yakutia, in terms of a vivid and typical representative of isolated areas with extreme temperature conditions. The analysis of area assessment of renewable energy and energy security strengthening of decentralized power supply systems is given. The research considers the worked out algorithm which determines the renewable energy attractiveness coefficient in connection with energy security assessment indicators. The document includes the results of the analysis of the energy situation in Yakutia with the help of geoinformation software product, the illustrative fragment of integrated information system modules. The implementation of the developed system results in fast analysis of occurring issues, indicators calculating as a foundation for strategic platform to manage energy security positions. The system assists to tackle the problems in advance.
\end{abstract}

\section{Introduction}

In order to tackle up-to-date electrification issues especially on the decentralized power supply areas, multidirectional power sources tend to be used. In the global energy network along with centralized energy system such as powerful electric plants using traditional energy sources and renewable energy sources small power plants with renewable energy sources are available for small enterprises and settlements. With distributed generation one could use local energy resources more effectively. The distributed features of renewable energy sources are logically fit to the distributed generation concept. The stand-alone renewable energy sources power plants integrated into the distributed generation network of different physical nature will really compensate the lack of electricity generation by any power plants according to the renewable energy changeability.

The effectiveness of renewable energy resources implementation is defined by the estimation factors of the energy potential, the awareness of landscape deployment, ecological estimation and so on. But it is not enough to feature the utmost energy source deployment in the centre of power system electrical loads.

There is a need for network topology changes due to changes in flows of power. Violation of the hierarchy system of energy requires the presence of intellectual management components or full-fledged networks with distributed generation within the specified region. Only when these conditions are met, it is possible to fully exploit the full potential of renewable energy.
Renewable power sources technologies in the context of "smart" power grid take place in recent trends of world energy technology. World energy community increasingly apply to development of "green" energygenerating power at the expense of renewable sources, and this type of generation results in the creation of distributed energy concept. According to experts'views of the international seminar organized in the framework of the project APEC "Distributed generation and local energy for development in island and remote APEC territories", the most promising regions of Russia for the development of microgrid are the territories of North: the Republic of Sakha (Yakutia), Kamchatka and Transbaical Region. Yakutia is one of the brightest examples among specific areas with harsh conditions of energy facilities operation with the infrastructural isolation and susceptibility to economic worsening. Yakutia is the leader in large-scale operation of small power energy in territorial zone of discomfort. Undoubtedly rigorous demands are of great need to strengthen energy security (E.S), especially for Arctic zones. The specifics of how autonomous power supply system functions can threaten energy security in terms of infrastructural isolation and harsh climate [1,2]. Energy security monitoring of such territories through naturalresource orientation a priori determines the sustainable place of RES.

Urgent need and a supportive environment for implementing of distributed intellectual energy with optimal use of renewable energies contribute to its development, primarily in decentralized power supply systems.

*Corresponding author: viola75@mail.ru 


\section{Investigation methodology}

2.1. Renewable energy sources in assessing the level of energy security of the decentralized energy zones.

The properly and reasonably integrated distributed generation based on renewable energy sources and traditional power sources one can strengthen various directions of energy security with the help of sustainability and survivability of the electricity system. The emergence of an additional source of energy, functioning on the basis of local renewable energy resources will have a positive economic effect and in consequence will increase the competitiveness of Russian economy in the regions. At the same time an active environmental regulation, stricter requirements of environmental policies to improve environmental security, increase in the proportion of distributed generation on the basis of efficient technologies of the last generation allow to fully implementing the stimulus for the use of renewable energy. The study introduces groups of indicators for assessing the degree of attractiveness and the availability of renewable energy resources, comprehensively characterizing blocks of resource availability, environmental vulnerability and energy local security energy zones of the North and Arctic zones [3,4].

Attractiveness factor of the territory to integrate RES (under territory capacity condition) in isolated power system has been considered in calculating and analytical dependences using a variety of factors: potential resource RES, degree of decentralization, the extent of state support, the ability to connect to the central power supply, the cost of electricity, the social status of the population and its capacity to pay. The method of hierarchy analysis was used. When making up the matrix of paired comparisons preference of elements of defined hierarchical level was determined by the criteria of "Increased reliability of ASES/Cost reduction (fig. 1) to determine the degree of importance of parameters by adding factors for the attraction of development RES.

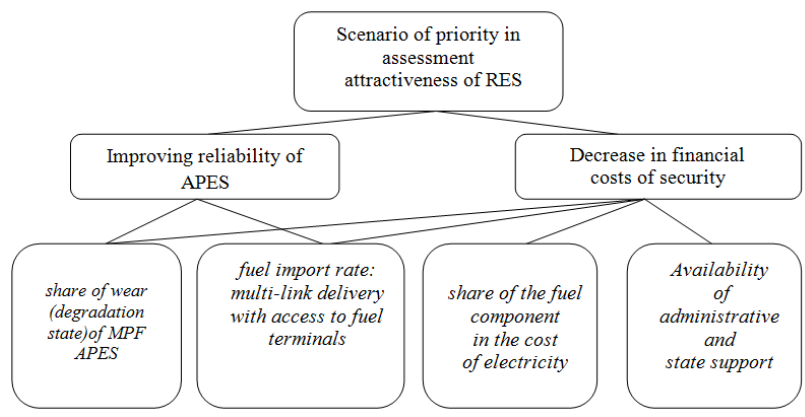

Fig. 1. The hierarchy structure by two criteria in the priority of the alternative for validity of the attractiveness of renewable energy sources

And similarly it was conducted with the criterion of "Availability of Typical ASES without RES" for the factor elements of attractiveness lack. Priorities for weight values factors were confirmed by rank expert evaluation of indicators in the list, but in the long term it requires a systematic experts questioning from the point of view of changes in modern energy and the position of decentralized zone.

For each decentralized zone which is not appropriate to be connected to the centralized power system background index can be used to the RES development, calculated by minimax method if minimum value is " 0 " and maximum value is " 1 ". The features are made for assessment application, which are partly reflected in the above stated attractiveness factors and neutralized RES development in differentiated areas of 1 and 2 types in accordance with k_ (RES supply) and ecozones:

- Resource-territory: particular characteristics - F_ (fuel delivery) - reflects the risk of access to fuel supplies; $F_{-}$(fuel in electricity) - reflects isolation of the territory;

- Social and energy: particular characteristics - 1/F_ (social subsidized tariff) $; \mathrm{F}_{-}$(power cost) $; \mathrm{F}_{-}$(degradation of major industrial funds) Index calculation is based on standard techniques for ranking objects which are often used in research:

$$
P_{i k}=\frac{\sum_{n}\left[\left(F_{i j k \max }-F_{i j k}\right) /\left(F_{i j k \max }-F_{i j k \min }\right)\right]}{n k}
$$

where $\mathrm{P}_{-} i k-$ value of $\mathrm{\kappa}$ type of particular characteristics in $i$ decentralized energy zone of North district and arctic zone;

$n k$ - the number of indicators for assessing $\mathrm{k}$ type of characteristics

$\mathrm{F}_{-} i j k$ - the value of the $\mathrm{j}$ - figure in $\mathrm{i}$ - decentralized powerzone for k- type of characteristic;

F_ijkmax - the value of the j- figure of $\mathrm{i}$ - decentralized powerzone with the maximum value, related to $\mathrm{k}$ - type of characteristics;

F_ijkmin - the value of the j-figure of $i$ - decentralized powerzone with a minimum value, related to k- type of characteristics.

Integral value by background index for the development of RES in the territory of the decentralized powerzone is calculated as weighted average amount of particular characteristics taking into account the weighted average weight of $\mathrm{k}$ - characteristics in accordance to expert evaluation of Ek:

$$
Y_{i}=\sum P_{i k} \cdot E_{k}+\text { evaluation } L E_{i m}
$$

where LE_im - ecological immunity level, dealing with areas belonging to vulnerable ecozones, where RES can be of interest. Such territories are grouped in a separate cluster.

During the research work on expert opinion on territorial resource characteristic it was concluded that it has the priority to background index when taking a decision on the development of renewable energy.

2.2. The attractiveness of renewable energy sources in the policy of strengthening the energy security.

The attractiveness of RES development is a general characteristic of full list of factors and funds, which distinguish their resources from traditional energy resources and other decisions in diversifying energy and make them interesting to improve reliability autonomous power supply systems (APES) in strengthening ES. 
The set of indicators and means of possible and necessary implementation of RES attractiveness featured by specific decentralized zones with developed assessment of ES level requires the effect determination [5] (economic reasonableness, substitution fuel resources and reservation), social and environmental (avoidance of replaced generating capacity emissions), operational reliability improving, etc.) depending on the implementation or exclusion factor of the attractiveness of RES development. Therefore, the definition of the attractiveness RES indicator while monitoring ES becomes quite a sufficiently comprehensive study for which is illustrated by the following diagram (fig. 2).

The given indicator is included in the indicators list and characterizes a preliminary attractiveness assessment and favourability climate degree of the local territory for RES development. The determination of the attractiveness indicator is an important basis for the factors analysis to achieve an optimum variant of APES involving RES as a strengthening ES resource availability, fuel and electricity supply reliability, ecological admissibility and socio-economic impact.

The need to improve the increase of APES reliability of decentralized energy zones is defined as an objective premise for investment in the development of renewable energy. Investment potential determines the ability to implement the possibilities the definition of which is determined by the ES indicators, as private investment potentials (resource related, industrial, and economic, etc.). This indicator is defined by a slightly different semantic meaning i.e. investment attractiveness in terms of where these investments are of great need, and not where they are easily refunded. Position indicator is realized through ensuring comfortable conditions for life as opposed to benefit from investment.

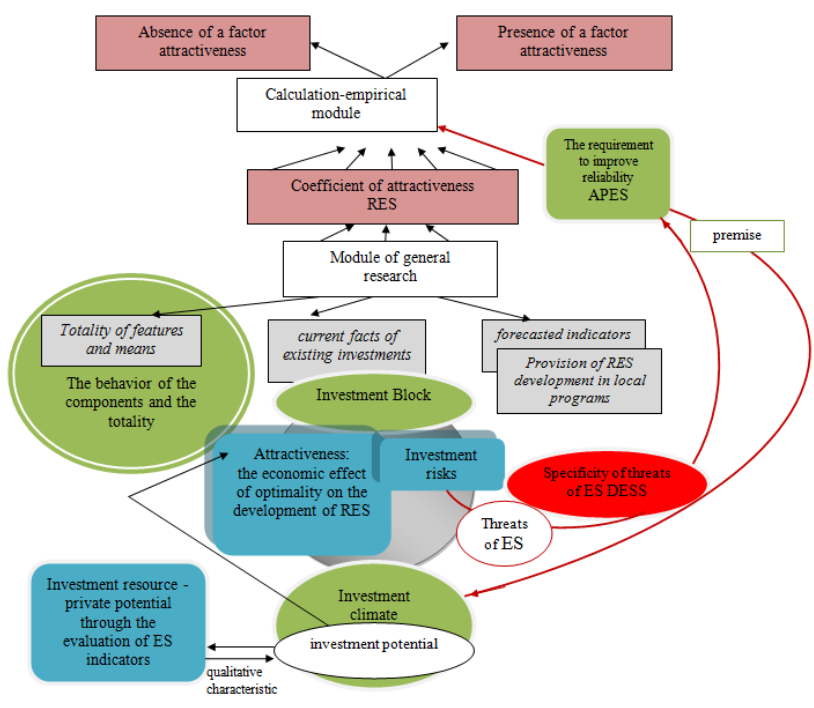

Fig.2. The tree of stages in determining the factor of attractiveness RES (where DESS - decentralized electrical supply systems)

It is noteworthy that social investments as parts of social programs should be important to realize for the more profitable companies within the country. It is a common thing for Russia. The aims of these programmes reflect traditions and practical needs and have much in common with other countries programmes: social infrastructures in the given region, education for the area benefit, support to Small Northern Peoples (e.g."NOVATEK company).

It is particular investment in autonomous energy sufficiently transparent and is substantiated by a large number of factors. Low consumers paying capacity does not include investment component in tariff. The current tariff policy does not take into account the prevailing features of regional power energy system and does not allow you to realize the objectives of socio-economic development in the northern part in the field of energy infrastructure.

\section{Development tools of security energy monitor system}

\subsection{Consolidated set of visualized data analysis}

Interactive chart (fig. 3) is created on current power energy situation in Yakutia by geo-information software ArcGIS. It displays, integrates and synthesizes a layer of administrative-territorial division of Yakutia. The results of cluster and price formation analysis of multidimensional SE indicators classification of Yakut Republic renewable energy potential(cluster level of ES, resource adequacy, affordability clusters, ecological and technological resource clusters, solar energy clusters, wind energy resource clusters, hydropower resource clusters, bioenergy resources clusters). The chart is created on the basis of prior models, data mining, (fig. 2 ). It represents an interactive window, which allows you to visualize, examine and review the status of local and centralized energy, highlight promising territory for power plants construction on the renewable energy basis. This model can be a device for preliminary monitoring of vulnerable and weak ES position.

\subsection{Information scheme of the modeled complex of assessment of energy security level.}

In the course of further research work to define the best ASES options geographic information platform SakhaGis and PHPMyAdmin are used, which is a Web interface that you can use to administer a MySQL Server run commands and view the contents of the tables and databases through a Web browser. As databases the following information fronts were selected: cards: SakhaGis (maps, satellites), Google (maps, satellites), WRDC (World Radiation Data Centre), NASA SEE (satellite), Rosreestr, TopoMAP, ESRI (satellite); Base enterties, districts, settlements of RF (Toster); TEC database of Sakha (Yakutia) (rushydro, DGKinfo, JSC Sahajenergo, etc.).

Integrated information system (IIS) supports a single repository that serves to create, manage, and deliver spatial data (fig. 4) necessary for indicators analysis and assessment, to obtain supporting multi-factor identity information about territory with geolocation energy 
facilities and settlements, energy security level monitoring facilities and the possibilities for RES in vulnerable geo-referenced clusters (fig. 5).

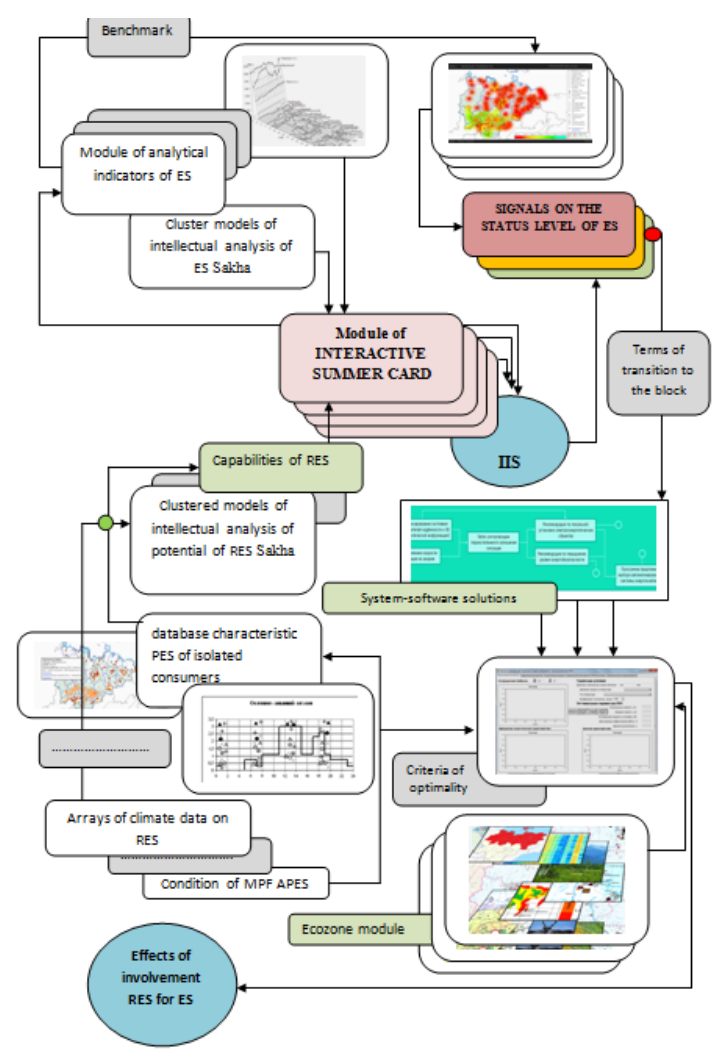

Fig. 3. Interactive summary map of the results of cluster analysis of energy security and renewable energy potential

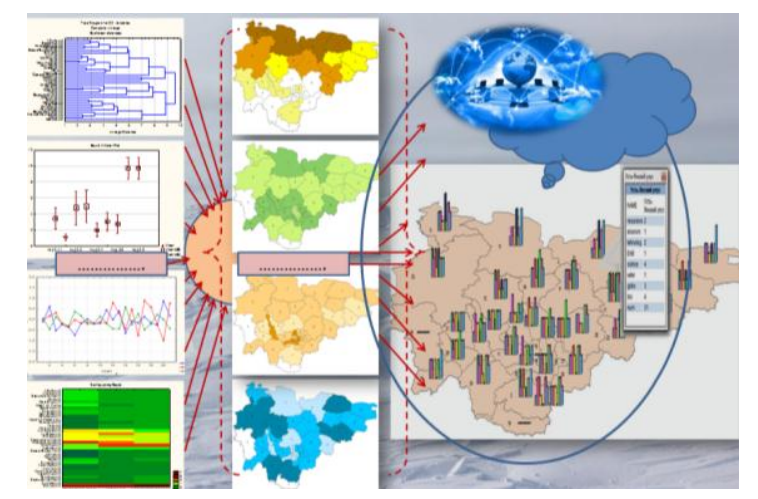

Fig.4. The fragment of the separate basic and accompanying modules in the block diagram of the integrated information system (IIS)

It is supposed to make queries to different databases and amounts of information. There is the possibility of accessing the cluster development on the best options and criteria APES building [6] (including RES, fig. 4) through intelligent algorithm choice. The possibility of transition to the choice of the appropriate solution with RES is possible only with the removal of the previous level signal with the worst index of Sakha Republic (Yakutia). The transition possibility to the analytical block to upgrade the input indicators data that increase problems rate analysis and calculate their up-to-date efficient values as the basis for the formation of strategic platform on ES positions management. Further widening of automatic system of indicators calculation used in the process of attractiveness RES rate with defining the levels of protection for user login is supposed to occur.

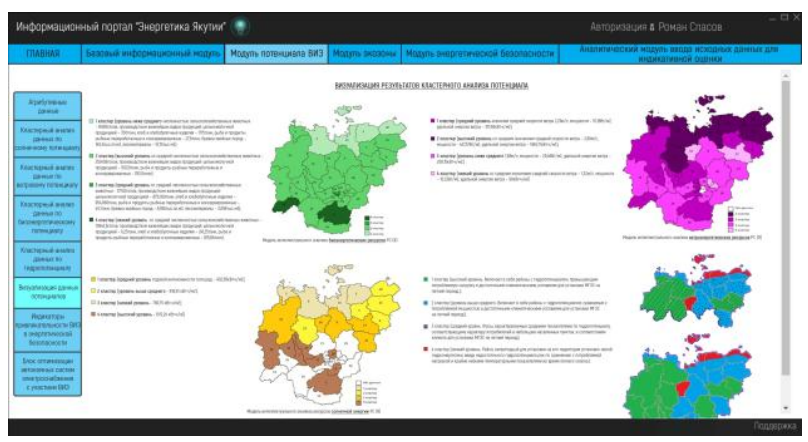

Fig. 5. Information window of the integrated system "Results of cluster analysis of the potential of renewable energy sources".

\section{Conclusions}

Currently, there exist cartographic models of territories zoning with the designation of the optimal level of renewable energy development. But they do not illustrate symbiosis position of energy facilities with different principles and a specific RES location in the criteria of ASES structure optimization. This gives the reinforcing effect for ES strengthening of decentralized powerzones with the most important indicative figures the current value of which should be improved firstly and visualized by the system. This system is an effective and convenient tool that makes possible to submit results to the users and gives the possibility to calculate the indicators with the choice of the most optimal power supply system with RES.

In the research work the emphasis is put on the isolated areas of the North and Arctic zones which are of great need in applying RES in order to strengthen energy security and improving quality of human life. And for the greater part of the area population it results in preservation of indigenous culture and the way of life. Renewable energy on such territories can compete with traditional expensive electricity and heating facilities. It is not argued, everyone acknowledges it as clear development logic. The specificity of decentralized North areas is an advantage for RES projects implementation under severe conditions. Intellectual monitoring system makes it possible to accelerate the process of socio-economic and environmentaltechnological effects given by the development of renewable energy sources, which reflects their explicit opportunity to consider Energy security strengthening.

\section{Certification}

The research work was presented at the International Arctic Summit "Arctic and shelf projects: perspectives, 
innovation and regional development" "Arctic-2018, St. Petersburg, on the III International Conference "Arctic: shelf projects and sustainable development of regions" Arctic-2018 Moscow Chamber of Commerce and Industry of the RUSSIAN FEDERATION, the allRussian Conference of regional energy policy-2018, Irkutsk Melentiev Energy Systems Institute of the Siberian Branch of the RAS.

\section{References}

1. Kiushkina $V$. Analysis specificity of energy security in autonomous systems of North power supply. Power policy 5, 52 (2016).

2. Kiushkina V. Energy security assessment model for autonomous power supply systems of the Northern Territory. SCIENCESTUDIES. 6 (2016)

3. Kiushkina VRenewable energy sources in the energy security of local energy zones. Industrial energy. 9, 44 (2016)

4. Kiushkina V. Ochepkova I. Cluster analysis of the potential of renewable energy sources in the Republic of Sakha (Yakutia). SCIENCESTUDIES. 4 (2014)

5. Kiushkina V. Effects of RES involvement in monitoring the state of energy security of the northern and Arctic zones of the Russian Federation. Energy policy. 4, 109 (2018)

6. Lukutin B., Kiushkina V. Wind power plants in the autonomous power industry of Yakutia, 2006. 